\title{
An Empirical Analysis of Same-Sex Marriage in Taiwan
}

\author{
Wen-Shai Hung \\ Department of Business Administration, Providence University, Taiwan \\ Email: wshung@pu.edu.tw
}

How to cite this paper: Hung, W.-S. (2018) An Empirical Analysis of Same-Sex Marriage in Taiwan. Theoretical Economics Letters, 8, 3301-3312.

https://doi.org/10.4236/tel.2018.815204

Received: September 20, 2018

Accepted: November 19, 2018

Published: November 22, 2018

Copyright (C) 2018 by author and Scientific Research Publishing Inc. This work is licensed under the Creative Commons Attribution International License (CC BY 4.0).

http://creativecommons.org/licenses/by/4.0/

\begin{abstract}
This paper examines the factors influencing same-sex marriage in Taiwan. The data used is from the 2015 Survey Research on Attitudes toward the Death Penalty and Related Values in Taiwan, which focused on knowledge, attitudes toward the death penalty, and the concepts of social, political, and law values. The sample ages are from 21 to 94 . The method used is probit modelling for examining the influences on same-sex marriage issues in Taiwan. The main empirical results find that older people, men, aboriginal people, persons with medium educational attainment, people with higher income, Christian and Catholic, those who agree with killing stray cats or dogs, agreeing with the concept of people over freedom, and over human rights are less likely to have tolerant views of same-sex marriage behaviours. In contrast, people agreeing with the values of divorce, abortion, euthanasia, and men who favour military human rights are more likely to accept same-sex marriage in their comprehensive lives. Taiwan is no longer under martial law and has a multi-party system of democratic governance; the current ruling party may support gay rights and need to draft the law of same-sex marriage in the near future.
\end{abstract}

\section{Keywords}

Same-Sex Marriage, Divorce, Abortion, Euthanasia, Probit Model

\section{Introduction}

The traditional Chinese culture has five thousand years of history and a lot of secret codes in Chinese words. For example, the word “好” combines “女” and “子”, that means "woman and man", "girl and boy", or "daughter and son" together means "good", "correct", or "promise \& agree". Traditional marriage has been defined as a religious and legal commitment between a man and woman, as 
well as the ultimate expression of love. Homosexuality was viewed with disdain, and marriages between same-sex couples were forbidden [1]. Therefore, the issues of lesbians, gays, bisexuals, transgender, and queer or questioning (LGBTQ) are difficult for people to understand and accept in the traditional Chinese and Asian societies.

However, homosexual relationships are slowly gaining acceptance, as homosexuals have become vocal in fighting for their right to marry since the early 1990s. With an increase in tolerance for homosexuality in society, the controversy over the legalization of gay marriage has been disputed among people in many nations. While the majority of the population believes that the legalization of same-sex marriage or gay marriage will have a negative impact on society, gay activists claim that it is against basic civil rights to prohibit them from marrying [2].

According to the report on Changing Attitudes on Gay Marriage in the USby the Pew Research Centre [3], which examined public opinion, American opposition to same-sex marriage decreased from 57\% in 2001to 35\% in 2016. For the generation factor, the younger generations express higher levels of support for same-sex marriage, but the older generations also have become more supportive of same-sex marriage in the past decade. For religious affiliation, among people who are religiously unaffiliated, a solid majority have supported same-sex marriage since 2001 and 58\% of Catholics now support same-sex marriage, as do nearly two-thirds of white mainstream Protestants (64\%). Support for same-sex marriage among black Protestants and white evangelical Protestants remains lower than it is among other religious groups. Both groups, however, have become somewhat more accepting of same-sex marriage over the last decade. For the political parties, $70 \%$ of Democrats favour same-sex marriage, as do $61 \%$ of independents. Smaller shares of Republicans favour same-sex marriage, about $33 \%$, although they also have become more supportive since 2001. For political ideology, support for same-sex marriage now stands at $78 \%$ among self-described liberals and 66\% among moderates. Far fewer conservatives (29\%) support same-sex marriage. For the race factor, roughly one-third of both whites and blacks expressed support for same-sex marriage in 2001. Today, 57\% of whites support same-sex marriage, as do $42 \%$ of blacks. For the gender factor, support for same-sex marriage has risen among both men and women in recent years. Today, $58 \%$ of women and $52 \%$ of men support same-sex marriage [3].

The history of lesbians, gays, bisexuals, transgender, and queer or questioning (LGBTQ) has seen long periods of persecution, succeeded by understanding and acceptance in Taiwan. Today, Taiwan is no longer under martial law and has a multi-party system of democratic governance; the Democratic Progressive Party (DPP, ruling party) in particular supports gay rights. Furthermore, Buddhism and Taoism offer little resistance in their doctrine toward the LGBTQ community. The only religious element that opposes issues concerning the LGBTQ community is Christian groups, who comprise just $5 \%$ of the Taiwanese population. However, the traditional Taiwanese emphasis on filial piety, stemming 
from Confucian doctrine also plays a role in this opposition [4].

Teng \& Huang [5] presented "A Study of Legalization of Same-Sex Marriage in Taiwan", which evaluated the necessity of drafting a law of same-sex marriage in Taiwan. However, few empirical studies have considered individual knowledge, attitudes, and social values concerning same-sex marriage in Taiwan. This paper tries to fill this gap and investigates the factors influencing attitudes to same-sex marriage in Taiwan. Finally, the results find that older people, men, aboriginal people, persons with medium educational attainment, people with higher income, Christian and Catholic, those who agree with killing stray cats or dogs, agreeing with the concept of people over freedom, and over human rights are less likely to have tolerant views of same-sex marriage behaviours. In contrast, people agreeing with the values of divorce, abortion, euthanasia, and men who favour military human rights are more likely to accept same-sex marriage in their comprehensive lives.

\section{Some Basic Facts about Same-Sex Marriage in Taiwan}

The discussion of same-sex marriage in Taiwan began around the year 2000. So far, the Taiwanese government has not yet recognized the legal status of same-sex marriage. Teng \& Huang [5] presented "A Study of Legalization of Same-Sex Marriage in Taiwan", which evaluated the necessity of drafting the law of Same-Sex Marriage in Taiwan.

There are some reasons against introducing same-sex marriage (SSM) into the law in Taiwan: 1) it may deplete the country's huge resources, affecting the government's ability to develop the economy. 2) SSM in many countries has led to social conflict. If hastily promoted in Taiwan it is bound to cause social disputes and internal friction. 3) The European Court of Human Rights and the Supreme Court of the United States have not made a decision; Taiwan should not be the first Chinese experiment. 4) SSM does not have the possibility of natural fertility, thus it is not conducive to Taiwan's family continuity and population development. 5) AIDS is the most common STD among men, and has become one of the top ten causes of death. 6) SSM is not in the best interest of a minor child [6].

In contrast, there are some reasons for the same-sex marriage, including: 1) for human rights and freedom: everyone has the same rights and freedom to do what they want, as long as it does not cause harm to the society, and decisions made by others should be respected [7]. 2) For legal benefits: they can receive social security, Medicare and disability benefits for their spouses. 3) For health benefits of marriage: The health benefits of marriage have been observed around the world and studies have shown that marriage improves people's health, both physically and psychologically [8]. 4) For social benefits: If SSM were to be legalized, the number of child adoptions would increase, as would social stability [1].

Table 1 summarises lesbian, gay, bisexual, transgender (LGBT) rights in Taiwan. Taiwan has been regarded as one of the most progressive states in Asia. 
Table 1. Summary of LGBT rights in Taiwan.

\begin{tabular}{|c|c|}
\hline Terms & Rights \\
\hline Same-sex sexual activity legal & Always legal \\
\hline Equal age of consent & Always equal \\
\hline Anti-discrimination laws in employment & Since 2007 \\
\hline Anti-discrimination laws in education & Since 2004 \\
\hline Anti-discrimination laws in the provision of goods and services & No \\
\hline $\begin{array}{l}\text { Anti-discrimination laws in all other areas } \\
\text { (incl. indirect discrimination, hate speech) }\end{array}$ & No \\
\hline Same-sex marriage(s) & $\begin{array}{c}\text { Not yet in effect. } \\
\text { To be legal by } 24 \text { May } 2019\end{array}$ \\
\hline Recognition of same-sex couples & $\begin{array}{l}\text { Since 2015, partnership } \\
\text { registration performed in } \\
\text { all municipalities except } \\
\text { four counties; very } \\
\text { limited protections only }\end{array}$ \\
\hline Stepchild adoption by same-sex couples & No, Proposed \\
\hline Joint adoption by same-sex couples & No, Proposed \\
\hline LGB people allowed to serve in the military & Yes, Since 2002 \\
\hline Right to change legal gender (surgery not required since 2015) & $\begin{array}{l}\text { Yes, Since 2008; surgery } \\
\text { required; removal of surgery } \\
\text { requirement proposed }\end{array}$ \\
\hline Conversion therapy outlawed & Since 2018 \\
\hline Access to IVF for lesbians & No \\
\hline Commercial surrogacy for gay male couples & $\begin{array}{l}\text { No, Banned for heterosexual } \\
\text { couples as well }\end{array}$ \\
\hline MSMs (Men who have sex with men) allowed to donate blood & No, 5 year deferral period \\
\hline
\end{tabular}

Both male and female same-sex sexual activity are legal, however, same-sex couples and households headed by same-sex couples are not eligible for the legal protections available to opposite-sex couples.

\section{Data}

\subsection{Data Source}

The data set used is from the 2015 Survey Research on Attitudes toward the Death Penalty and Related Values in Taiwan by Hei-yuan Chiu [9], which focused on knowledge, attitudes toward death penalty, and the concepts of social, political, and law values [9]. This paper only examines the factors influencing same-sex marriage in Taiwan. The sample ages are from 21 to 94 . The total sample has 2039 observations, but the effective sample only has 1154 observations, who have completely answered all the questions about same-sex marriage issues. 


\subsection{Variables Specification}

Probit analysis examines the influences on same-sex marriage issues in Taiwan. Hence the dependent variable is simply specified as $y=1$ if the respondents or their family agree with same-sex marriage and zero otherwise. Table 2 shows that $64.4 \%$ observations agree with same-sex marriage ideas. The explanatory variables include 1) Individual characteristic variables: age, gender, race, and education. 2) Economic variables: individual earnings and family income. 3) Social valuation variables: religions, freedom, human rights, social system, divorce, abortion, and killing stray dogs and cats. A full definition of the variables and summary statistics of the sample are given in Table 2.

\section{Empirical Specification}

This paper uses Probit modelling to examine the influences on same-sex marriage issues in Taiwan. Let $y$ represent the choice of same-sex marriage issues ( $y=1$ if agree with same-sex marriage, 0 otherwise) and let the two outcomes, be described by the state-specific utilities $U_{y}^{*}$ [10] [11]:

$$
\begin{aligned}
& U_{y=1}^{*}=x^{\prime} \beta_{1}+u_{1} \\
& U_{y=0}^{*}=x^{\prime} \beta_{0}+u_{0}
\end{aligned}
$$

where $x^{\prime}$ represents a common set of control variables, $\beta_{0}$ and $\beta_{1}$ are vectors of unknown parameters, $u_{0}$ and $u_{1}$ represent unobservable (state-specific) taste components. Under this characterisation, an individual will agree with same-sex marriage if the utility to be had when agreeing with same-sex marriage (denoted $U_{y=1}^{*}$ ) exceeds the utility to be had when not agreeing with same-sex marriage (denoted $U_{y=0}^{*}$ ). An individual will agree with same-sex marriage if $U_{y=1}^{*}>U_{y=0}^{*}$, and therefore the decision to agree with same-sex marriage $y=1\left(U_{y=1}^{*}-U_{y=0}^{*}>0\right)$.

Consequently the observation rule (1) and (2) can be rewritten as:

$$
\begin{aligned}
y & =1\left(U_{y=1}^{*}>U_{y=0}^{*}\right) \\
& =1\left(x^{\prime} \beta_{1}+u_{1}>x^{\prime} \beta_{0}+u_{0}\right) \\
& =1\left[\left(u_{1}-u_{0}\right)>-x^{\prime}\left(\beta_{1}-\beta_{0}\right)\right]
\end{aligned}
$$

Clearly, both sets of parameters $\beta_{0}$ and $\beta_{1}$ cannot be identified. However, the difference $\beta_{1}-\beta_{0}$ can be identified, and implicitly parameterize the choice model as:

$$
y=1\left(y^{*}>0\right)
$$

where $y^{*}=x^{\prime}\left(\beta_{1}-\beta_{0}\right)+\left(u_{1}-u_{0}\right)=x^{\prime} \beta+u$. Maximum likelihood estimation (hereafter, MLE) considers the probability of observing a sample of behavioural outcomes and characteristics. Consider a sample of $n$ observations $\left\{y_{i}, x_{i}\right\}$ drawn at random from a population, where $y_{i}$ is binary. Assuming the observability criterion $y_{i}=1\left(y_{i}^{*}>0\right)$ for a latent variable equation of the form $y_{i}^{*}=x_{i}^{\prime} \beta+u_{i}$, and, assuming that the distribution of $u_{i}$ is standard normal and 
Table 2. Descriptive statistics of variables.

\begin{tabular}{|c|c|c|c|c|c|}
\hline Variable & Description & Mean & Std. Dev. & Min & Max \\
\hline SSM & $1=$ Agree with same-sex marriage, $0=$ Otherwise & 0.644 & $(0.479)$ & 0 & 1 \\
\hline Age1 & $1=$ Aged from 21 to $30,0=$ Otherwise & 0.184 & $(0.388)$ & 0 & 1 \\
\hline Age2 & $1=$ Aged from 31 to $40,0=$ Otherwise & 0.231 & $(0.421)$ & 0 & 1 \\
\hline Age3 & $1=$ Aged from 41 to $50,0=$ Otherwise & 0.242 & $(0.428)$ & 0 & 1 \\
\hline Age4 & $1=$ Aged from 51 to $60,0=$ Otherwise & 0.197 & $(0.398)$ & 0 & 1 \\
\hline Age 5 & $1=$ Aged from 61 to $70,0=$ Otherwise & 0.094 & $(0.292)$ & 0 & 1 \\
\hline Age6 & $1=$ Aged from 71 to $94,0=$ Otherwise & 0.050 & $(0.218)$ & 0 & 1 \\
\hline Gender & $1=$ Men, $0=$ Women & 0.548 & $(0.498)$ & 0 & 1 \\
\hline Race1 & $1=$ Fujianese, $0=$ Otherwise & 0.733 & $(0.442)$ & 0 & 1 \\
\hline Race2 & $1=$ Hakka, $0=$ Otherwise & 0.117 & $(0.322)$ & 0 & 1 \\
\hline Race3 & $1=$ Aboriginal, $0=$ Otherwise & 0.010 & $(0.101)$ & 0 & 1 \\
\hline Race 4 & $1=$ Mainlander, $0=$ Otherwise & 0.131 & $(0.337)$ & 0 & 1 \\
\hline Race5 & $1=$ New people, $0=$ Otherwise & 0.008 & $(0.088)$ & 0 & 1 \\
\hline Edul & $1=$ Informal, $0=$ Otherwise & 0.012 & $(0.113)$ & 0 & 1 \\
\hline Edu2 & $1=1-6$ years of schooling, $0=$ Otherwise & 0.081 & $(0.272)$ & 0 & 1 \\
\hline Edu3 & $1=7-9$ years of schooling, $0=$ Otherwise & 0.110 & $(0.313)$ & 0 & 1 \\
\hline Edu4 & $1=10-12$ years of schooling, $0=$ Otherwise & 0.268 & $(0.442)$ & 0 & 1 \\
\hline Edu5 & $1=13-16$ years of schooling, $0=$ Otherwise & 0.436 & $(0.496)$ & 0 & 1 \\
\hline Edu6 & 17 years and over of schooling, $0=$ Otherwise. & 0.093 & $(0.290)$ & 0 & 1 \\
\hline Earnings & Earnings $=\log$ (individual average earnings). & 10.287 & $(0.863)$ & 8.517 & 12.206 \\
\hline Income & Income $=\log$ (household average income). & 11.109 & $(0.797)$ & 8.517 & 12.899 \\
\hline Religion1 & $1=$ Buddhism, $0=$ Otherwise & 0.239 & $(0.427)$ & 0 & 1 \\
\hline Religion2 & $\begin{array}{c}1=\text { Traditional (included Taoism and } \\
\text { Folk belief), } 0=\text { Otherwise }\end{array}$ & 0.452 & $(0.498)$ & 0 & 1 \\
\hline Religion3 & $1=$ Christian and Catholicism, $0=$ Otherwise. & 0.081 & $(0.274)$ & 0 & 1 \\
\hline Religion4 & $1=$ Islam and others, $0=$ Otherwise & 0.005 & $(0.072)$ & 0 & 1 \\
\hline Religion5 & $1=$ No religion, $0=$ Otherwise & 0.222 & $(0.416)$ & 0 & 1 \\
\hline Divorce & $1=$ Agree with divorce, $0=$ Otherwise & 0.658 & $(0.475)$ & 0 & 1 \\
\hline Abortion & $1=$ Agree with abortion, $0=$ Otherwise & 0.388 & $(0.486)$ & 0 & 1 \\
\hline Animal & $\begin{array}{l}1=\text { Agree with killing the stray } \\
\text { (homeless) dogs and cats, } 0=\text { Otherwise. }\end{array}$ & 0.301 & $(0.459)$ & 0 & 1 \\
\hline Euthanasia & $1=$ Agree with euthanasia, $0=$ Otherwise & 0.762 & $(0.426)$ & 0 & 1 \\
\hline Freedom & $\begin{array}{l}1=\text { Society is chaotic, people } \\
\text { with too freedom, } 0=\text { Otherwise. }\end{array}$ & 0.414 & $(0.493)$ & 0 & 1 \\
\hline $\begin{array}{l}\text { Human } \\
\text { Right1 }\end{array}$ & $1=$ People with human right, $0=$ Otherwise & 0.856 & $(0.351)$ & 0 & 1 \\
\hline $\begin{array}{c}\text { Human } \\
\text { Right2 }\end{array}$ & $1=$ Army with human right, $0=$ Otherwise. & 0.562 & $(0.496)$ & 0 & 1 \\
\hline
\end{tabular}

Note: 1) According to the 2015 Survey Research on Attitudes toward Death Penalty and Related Values in Taiwan, total sample has 2039 observations, but the effective sample only has 1154 observations, who have completely answered all the questions for this issue. 2) The variables of Earnings and Income are presented by individual average earnings and household average income per month in Taiwan and measured in log form. 
independent across observations, MLE solves for the parameter vector $\beta$ which is most likely to have generated the data $\left\{y_{i}, x_{i}\right\}$. For any vector $\beta$, the probability of observing the outcome $y_{i}$ conditional on the data $x_{i}$ is

$$
L\left(\beta \mid x_{i}\right)=\prod_{i=1}^{n} \operatorname{Pr}\left(y_{i}=0 \mid x_{i} ; \beta\right)^{1-y_{i}} \cdot \operatorname{Pr}\left(y_{i}=1 \mid x_{i} ; \beta\right)^{y_{i}}
$$

Taking a natural log to obtain:

$$
\ln L\left(\beta \mid x_{i}\right)=\sum_{i=1}^{n}\left[\left(1-y_{i}\right) \cdot \ln \operatorname{Pr}\left(y_{i}=0 \mid x_{i} ; \beta\right)+y_{i} \cdot \operatorname{Pr}\left(y_{i}=1 \mid x_{i} ; \beta\right)\right]
$$

For the probit model, the following conditions for probability hold:

$$
\begin{gathered}
\operatorname{Pr}\left(y_{i}=1 \mid x_{i} ; \beta\right)=\Phi\left(x_{i}^{\prime} \beta\right) \\
\operatorname{Pr}\left(y_{i}=0 \mid x_{i} ; \beta\right)=1-\Phi\left(x_{i}^{\prime} \beta\right)
\end{gathered}
$$

where $\Phi(x)$ is the standard normal cumulative distribution function. Substituting the above into (5) gives a conditional likelihood function of the form:

$$
\ln L\left(\beta \mid x_{i}\right)=\sum_{i=1}^{n}\left\{\left(1-y_{i}\right) \cdot \ln \left[1-\Phi\left(x_{i}^{\prime} \beta\right)\right]+y_{i} \cdot \ln \Phi\left(x_{i}^{\prime} \beta\right)\right\} .
$$

The first-order condition requires that:

$$
\frac{\partial \ln L\left(\beta \mid x_{i}\right)}{\partial \beta}=\sum_{i=1}^{n} \frac{\left[y_{i}-\Phi\left(x_{i}^{\prime} \beta\right)\right]}{\Phi\left(x_{i}^{\prime} \beta\right) \cdot\left[1-\Phi\left(x_{i}^{\prime} \beta\right)\right]} \cdot \phi\left(x_{i}^{\prime} \beta\right) \cdot x_{i}=0 .
$$

yielding the ML estimate $\tilde{\beta}$.

\section{Empirical Results}

Table 3 shows the coefficient estimates of agreement with same-sex marriage by probit model. First, for the benchmark individual, all explanatory variables take a value of zero. The benchmark individual in all cases is a single Fujianese woman, aged less than 30 , who has informal education, is non-Christian, and disagrees with the issues of divorce, abortion, killing the stray dogs and cats, euthanasia, freedom, and human rights of ordinary people and the army. This benchmark value is reflected in the constant variable in Table 3 , where the probability is

$$
\operatorname{Pr}\left(y_{i}=1 \mid x_{i} ; \beta\right)=\Phi(2.017)=0.978 .
$$

The effects on the probability of agreement with same-sex marriage can be calculated out for different demographic circumstances [12]. Holding other factors equal, how does the probability change for Gender (Males)? This situation models changes in the probability of agreement with same-sex marriage for men:

$$
\operatorname{Pr}\left(y_{i}=1 \mid x_{i} ; \beta\right)=\Phi(2.017-0.411)=0.946 .
$$

That is, men have a lower probability of agreement with same-sex marriage. Therefore, if the estimated coefficients are negative, the probabilities of agreement with same-sex marriage decrease. If the estimated coefficients are positive, then the probabilities of agreement with same-sex marriage increase. This result 
Table 3. Probit coefficient estimates.

\begin{tabular}{|c|c|c|c|c|c|c|}
\hline \multirow{2}{*}{$\begin{array}{c}\text { Cases } \\
\text { Variables }\end{array}$} & \multicolumn{2}{|c|}{ Overall } & \multicolumn{2}{|c|}{ Males } & \multicolumn{2}{|c|}{ Females } \\
\hline & Coef. & Std. Err. & Coef. & Std. Err. & Coef. & Std. Err. \\
\hline Age2 & $-0.315^{\star}$ & $(0.177)$ & -0.235 & $(0.231)$ & -0.474 & $(0.312)$ \\
\hline Age3 & $-0.814^{\star * *}$ & $(0.178)$ & $-0.658^{\star * *}$ & $(0.238)$ & $-1.076^{* * *}$ & $(0.310)$ \\
\hline Age4 & $-0.886^{\star * *}$ & $(0.187)$ & $-0.731^{\star \star *}$ & $(0.245)$ & $-1.133^{* * *}$ & $(0.329)$ \\
\hline Age5 & $-1.095^{\star * *}$ & $(0.220)$ & $-0.823^{* * *}$ & $(0.282)$ & $-1.548^{* * *}$ & $(0.386)$ \\
\hline Age6 & $-1.450^{* * *}$ & $(0.281)$ & $-1.549^{* * *}$ & $(0.376)$ & $-1.431^{* * *}$ & $(0.488)$ \\
\hline Gender & $-0.411^{\star * *}$ & $(0.103)$ & - & - & - & - \\
\hline Race2 & 0.105 & $(0.145)$ & 0.089 & $(0.200)$ & 0.169 & $(0.224)$ \\
\hline Race3 & $-0.810^{*}$ & $(0.432)$ & -0.418 & $(0.646)$ & $-1.366^{* *}$ & $(0.694)$ \\
\hline Race4 & -0.068 & $(0.143)$ & 0.102 & $(0.193)$ & -0.229 & $(0.225)$ \\
\hline Race5 & 0.236 & $(0.512)$ & 0.342 & $(0.610)$ & 0.400 & (1.076) \\
\hline Edu2 & $-1.153^{* * *}$ & $(0.430)$ & $-2.262^{\star *}$ & $(0.901)$ & -0.686 & $(0.516)$ \\
\hline Edu3 & $-0.738^{\star}$ & $(0.426)$ & $-1.558^{\star}$ & $(0.885)$ & -0.462 & $(0.526)$ \\
\hline Edu4 & -0.389 & $(0.423)$ & -1.237 & $(0.881)$ & -0.163 & $(0.532)$ \\
\hline Edu5 & -0.085 & $(0.428)$ & -1.132 & $(0.881)$ & 0.486 & $(0.555)$ \\
\hline Edu6 & 0.251 & $(0.470)$ & -0.591 & $(0.911)$ & 0.404 & $(0.655)$ \\
\hline Earnings & 0.065 & $(0.081)$ & -0.087 & $(0.124)$ & $0.213^{*}$ & $(0.125)$ \\
\hline Income & $-0.166^{\star *}$ & $(0.083)$ & -0.114 & $(0.118)$ & -0.195 & $(0.127)$ \\
\hline Religion3 & $-0.689^{\star * *}$ & $(0.167)$ & $-0.537^{\star *}$ & $(0.262)$ & $-1.052^{* * *}$ & $(0.237)$ \\
\hline Divorce & $0.945^{* * *}$ & $(0.101)$ & $1.042^{* * *}$ & $(0.137)$ & $0.928^{\star * *}$ & $(0.160)$ \\
\hline Abortion & $0.903^{* * *}$ & $(0.112)$ & $0.945^{\star * *}$ & $(0.148)$ & $0.756^{\star * \star}$ & $(0.187)$ \\
\hline Animal & $-0.341^{* * *}$ & $(0.104)$ & $-0.364^{\star * *}$ & $(0.141)$ & $-0.356^{* *}$ & $(0.166)$ \\
\hline Euthanasia & $0.343^{* * *}$ & $(0.120)$ & $0.320^{\star *}$ & $(0.164)$ & $0.388^{* *}$ & $(0.190)$ \\
\hline Freedom & $-0.217^{\star \star}$ & $(0.099)$ & $-0.304^{\star *}$ & $(0.137)$ & -0.094 & $(0.155)$ \\
\hline Human1 & $-0.317^{\star \star}$ & $(0.151)$ & -0.248 & $(0.201)$ & -0.385 & $(0.247)$ \\
\hline Human2 & $0.289^{* * *}$ & $(0.102)$ & $0.375^{\star * \star}$ & $(0.135)$ & 0.157 & $(0.166)$ \\
\hline Constant & $2.017^{\star *}$ & $(0.855)$ & $3.286^{\star *}$ & $(1.332)$ & 0.855 & (1.313) \\
\hline $\mathrm{N}$ & \multicolumn{2}{|c|}{1154} & \multicolumn{2}{|c|}{632} & \multicolumn{2}{|c|}{522} \\
\hline Log likelihood & \multicolumn{2}{|c|}{-466.546} & \multicolumn{2}{|c|}{-265.881} & \multicolumn{2}{|c|}{-187.531} \\
\hline LR chi2 (25) & \multicolumn{2}{|c|}{569.81} & \multicolumn{2}{|c|}{313.10} & \multicolumn{2}{|c|}{276.28} \\
\hline
\end{tabular}

Notes: 1) The omitted (reference) categories: Age1 for age groups dummy variable; female for gender; Race1 for race groups; and Edul for educational groups. 2) ${ }^{\star}$ Effect is significant at $\mathrm{p} \leq 0.10 ;{ }^{* *} \mathrm{p} \leq 0.05 ;{ }^{* * *} \mathrm{p}$ $\leq 0.01$; 3) Goodness of fit: the result of Log-likelihood ratio test can reject the hypothesis that all coefficients except the intercept are 0 at the 0.01 level. Considering the Gender variable, the LR chi2 of males and females are LR chi2 (24), respectively. 
of Gender is consistent with the attitudes on same-sex marriage by gender in the US.

Next, the estimated coefficients of Age2, Age3, Age4, Age5, Age6, Race3 (Aboriginal), Edu2, Edu3, y (Income), Religion3 (Christian \& Catholicism), Animal (Agree with killing the stray (homeless) dogs and cats), Freedom (Society is chaotic, people have too much freedom), and Human1 (People with human rights) variables are statistically significantly negative for agreement with same-sex marriage as shown in Table 3. This means that older men, Aboriginalpeople, people with medium educational attainment, higher household incomes, Catholics and other Christians, people agreeing with killing stray dogs and cats are less likely to agree with same-sex marriage. Specially, the result for Catholics and other Christians is consistent with the attitudes on same-sex marriage held by Catholics in the US.

In contrast, the estimated coefficients of Divorce, Abortion, Euthanasia, and Human 2 (Army with human rights) variables are statistically significantly positive for agree with same-sex marriage as shown in Table 3. This means that people agreeing with divorce, abortion, euthanasia, and army with human right are more likely to agree with same-sex marriage.

For gender factors, Table 3 shows that the estimated coefficients of Edu2, Edu3, and Freedom (society is chaotic, people have too much freedom) variables for men are statistically significantly negative for agreement with same-sex marriage. This means that men with medium educational attainments and men who consider that society is chaotic, people have too much freedom, are less likely to agree with same-sex marriage. Moreover, the estimated coefficient of the Race3 variable only for women is statistically significantly negative for agreement with same-sex marriage. This means that Aboriginal women are less likely to agree with same-sex marriage.

In contrast, Table 3 also shows that the estimated coefficient of y1 (individual average earnings) variable for women is statistically significantly positive for agreement with same-sex marriage. This indicates that women with higher earnings are more likely to agree with same-sex marriage. Furthermore, the estimated coefficient of the Human2 (army with human rights) variable for men is statistically significantly positive for agreement with same-sex marriage. This means that male army members are more likely to agree with same-sex marriage. In particular, this empirical result is consistent with the policy of LGB people being allowed to serve in the military since 2002 in Taiwan.

Furthermore, Table 4 shows the marginal effect of agreement with same-sex marriage. Although the results are similar to Table 3, some features are still of interest. For example, the variables of Age2, Age3, Age4, Age5, and Age6 have smaller marginal effects of agreement with same-sex marriage than Age1. This means that holding other variables constant, people with Age2 (aged 31 to 40) have a probability of agreement with same-sex marriage that is about 10.6 percentage points lower than a person with Age 1 (aged 21 to 30). Moreover, people with Age3 (aged 41 to 50), Age4 (aged 51 to 60), Age5 (aged 61 to 70), and Age6 
Table 4. Probit marginal effect estimates.

\begin{tabular}{|c|c|c|c|c|c|c|}
\hline Cases & \multicolumn{2}{|c|}{ Overall } & \multicolumn{2}{|c|}{ Males } & \multicolumn{2}{|c|}{ Females } \\
\hline Variables & $\mathrm{dy} / \mathrm{dx}$ & Std. Err. & $\mathrm{dy} / \mathrm{dx}$ & Std. Err. & $\mathrm{dy} / \mathrm{dx}$ & Std. Err. \\
\hline Age2 & $-0.106^{\star}$ & $(0.059)$ & -0.085 & $(0.084)$ & -0.137 & $(0.089)$ \\
\hline Age3 & $-0.275^{\star * *}$ & $(0.059)$ & $-0.240^{\star * *}$ & $(0.086)$ & $-0.310^{* * *}$ & $(0.086)$ \\
\hline Age4 & $-0.300^{* * *}$ & $(0.062)$ & $-0.267^{\star * *}$ & $(0.089)$ & $-0.327^{\star * *}$ & $(0.091)$ \\
\hline Age5 & $-0.371^{\star * *}$ & $(0.074)$ & $-0.301^{\star * *}$ & $(0.103)$ & $-0.446^{* * *}$ & $(0.108)$ \\
\hline Age6 & $-0.491^{* * *}$ & $(0.095)$ & $-0.566^{\star * *}$ & $(0.138)$ & $-0.413^{* * *}$ & $(0.139)$ \\
\hline Gender & $-0.139^{* * *}$ & $(0.034)$ & - & - & - & - \\
\hline Race2 & 0.035 & $(0.049)$ & 0.032 & $(0.073)$ & 0.049 & $(0.064)$ \\
\hline Race3 & $-0.274^{\star}$ & $(0.146)$ & -0.153 & $(0.236)$ & $-0.394^{* *}$ & $(0.201)$ \\
\hline Race4 & -0.023 & $(0.048)$ & 0.037 & $(0.071)$ & -0.066 & $(0.065)$ \\
\hline Race5 & 0.079 & $(0.173)$ & 0.125 & $(0.223)$ & 0.115 & $(0.310)$ \\
\hline Edu2 & $-0.391^{* * *}$ & $(0.146)$ & $-0.827^{\star \star}$ & $(0.331)$ & -0.198 & $(0.149)$ \\
\hline Edu3 & $-0.250^{*}$ & $(0.144)$ & $-0.570^{\star}$ & $(0.324)$ & -0.133 & $(0.151)$ \\
\hline Edu4 & -0.132 & $(0.143)$ & -0.452 & $(0.322)$ & -0.047 & $(0.153)$ \\
\hline Edu5 & -0.029 & $(0.145)$ & -0.414 & $(0.322)$ & 0.140 & $(0.160)$ \\
\hline Edu6 & 0.084 & (0.159) & -0.216 & $(0.333)$ & 0.116 & $(0.189)$ \\
\hline Earnings & 0.022 & $(0.027)$ & -0.031 & $(0.045)$ & $0.061^{\star}$ & $(0.036)$ \\
\hline Income & $-0.056^{* *}$ & $(0.028)$ & -0.042 & $(0.043)$ & -0.056 & $(0.036)$ \\
\hline Religion3 & $-0.233^{\star * *}$ & $(0.056)$ & $-0.196^{\star \star}$ & $(0.096)$ & $-0.303^{* * *}$ & $(0.068)$ \\
\hline Divorce & $0.320^{\star \star \star}$ & $(0.034)$ & $0.381^{* * *}$ & $(0.051)$ & $0.268^{\star \star \star}$ & $(0.047)$ \\
\hline Abortion & $0.306^{* * *}$ & $(0.037)$ & $0.345^{\star \star \star}$ & $(0.053)$ & $0.218^{\star * *}$ & $(0.053)$ \\
\hline Animal & $-0.115^{\star * \star}$ & $(0.035)$ & $-0.133^{\star * *}$ & $(0.051)$ & $-0.102^{\star *}$ & $(0.048)$ \\
\hline Euthanasia & $0.116^{* * *}$ & $(0.041)$ & $0.117^{\star \star}$ & $(0.060)$ & $0.112^{* *}$ & $(0.054)$ \\
\hline Freedom & $-0.073^{* *}$ & $(0.033)$ & $-0.111^{\star *}$ & $(0.050)$ & -0.027 & $(0.044)$ \\
\hline Human1 & $-0.107^{* * *}$ & $(0.051)$ & -0.091 & $(0.073)$ & -0.111 & $(0.071)$ \\
\hline Human2 & $0.098^{* * *}$ & $(0.035)$ & $0.137^{\star * *}$ & $(0.049)$ & 0.045 & $(0.048)$ \\
\hline $\mathrm{N}$ & \multicolumn{2}{|c|}{1154} & \multicolumn{2}{|c|}{632} & \multicolumn{2}{|c|}{522} \\
\hline Predicted Probability & \multicolumn{2}{|c|}{0.716} & \multicolumn{2}{|c|}{0.662} & \multicolumn{2}{|c|}{0.789} \\
\hline
\end{tabular}

Notes: 1) The dy/dx is for discrete change of dummy from 0 to $1 ; 2$ ) The omitted (reference) categories: Age1 for age groups dummy variable; female for gender; Racel for race groups; and Edul for educational groups; 3$){ }^{*}$ Effect is significant at $\mathrm{p} \leq 0.10 ;{ }^{* *} \mathrm{p} \leq 0.05 ;{ }^{* * *} \mathrm{p} \leq 0.01$.

(aged 71 to 94) have probabilities of agreement with same-sex marriage that are $27.5 \%, 30 \%, 37.1 \%$, and $49.1 \%$ respectively points lower than a person with Age 1 (aged 21 to 30). These results are consistent with the US findings that younger generations express higher levels of support for same-sex marriage.

In contrast, the variable of Divorce has a larger marginal effect than non-divorce. This result confirms that the divorcees have a probability of agreement with same-sex marriage that is about 32 percentage points higher 
than non-divorcees. Furthermore, the variables of Abortion, Euthanasia, and Human 2 variables also have larger marginal effects than otherwise. These results confirm that people agreeing with abortion and euthanasia have probabilities of agreement with same-sex marriage that are $30.6 \%$ and $11.6 \%$ points higher than those who disagree with abortion and euthanasia; The Army with human rights variable has a probability of agreement with same-sex marriage that is about 9.8 percentage points higher than otherwise.

\section{Conclusions}

This paper examines the factors influencing same-sex marriage issues in Taiwan. The main empirical results show that older men, aboriginal people, people with medium educational attainment, higher household income, Christian, people agreeing with killing the stray dogs and cats, people enjoyed freedom and human rights are less likely to agree with same-sex marriage. In contrast, people agreeing with the issues of divorce, abortion, euthanasia, and army with human rights are more likely to agree with same-sex marriage.

For the gender factor, only men with medium educational attainment and men who consider that society is chaotic, that people have too much freedom, are less likely to agree with same-sex marriage. In addition, only Aboriginal women are less likely to agree with same-sex marriage. In contrast, only women with higher earnings are more likely to agree with same-sex marriage. Male soldiers are also more likely to agree with same-sex marriage. In particular, this empirical result is consistent with the policy of LGB people being allowed to serve in the military since 2002 in Taiwan.

Furthermore, considering the factors of individual earnings and family income, women with higher earnings are significantly more likely to support same-sex marriage, but people with higher family income are less likely to express support for same-sex marriage.

However, the 2015 Survey Research on Attitudes toward the Death Penalty and Related Values in Taiwan has limited information about attitudes same-sex marriage and more in-depth research would be a useful next step. This paper only considers the effects of individual opinions and social values for influencing same-sex marriage issues. A possible later analysis could include more factors such as the traditional social valuation of filial piety and Confucian doctrine which could deeply affect same-sex marriage issues.

\section{Acknowledgements}

The author would like to thank the Center for Survey Research, RCHSS, Academia Sinica for providing the 2015 Survey Research on Attitudes toward Death Penalty and Related Values in Taiwan.

\section{Conflicts of Interest}

The author declares no conflicts of interest regarding the publication of this paper. 


\section{References}

[1] Law Teacher (2107) What Are the Reasons For and Against Gay Marriage? https://www.lawteacher.net/free-law-essays/family-law/what-are-the-reasons-for-an d-against-gay-marriage-law-essay.php

[2] Masci, D. (2008) Pew Forum: An Overview of the Same-Sex Marriage Debate. http://www.pewforum.org/2008/04/01/an-overview-of-the-same-sex-marriage-deba te/

[3] PRC (2016) Gay Marriage and Homosexuality. Religion \& Public Life, Pew Research Center. http://www.pewforum.org/topics/gay-marriage-and-homosexuality/

[4] Swinburne, T.F. (2017) Same-Sex Marriage in Taiwan. The Diplomat. http://thediplomat.com/2017/01/same-sex-marriage-in-taiwan/

[5] Teng, S. and Huang, T. (2013) A Study of Legalization of Same-Sex Marriage in Taiwan. Association of Chinese Police Research, 1-305. (In Chinese)

[6] Family (2016) Six Reasons against the Same-Sex Marriage into the Law. Taiwan Maintain Family. (In Chinese) https://taiwanfamily.com/related-posts/artice02

[7] Messerli, J. (2009) Same Sex Marriages: Pros \& Cons, Arguments For and Against. http://www.balancedpolitics.org/same_sex_marriages.htm

[8] Waite, L. and Gallagher, M. (2000) The Case for Marriage. Doubleday, New York.

[9] Chiu, H. (2015) Survey Research on Attitudes toward Death Penalty and Related Values in Taiwan (C00292) [data file]. Available from Survey Research Data Archive, Academia Sinica. https://doi.org/10.6141/TW-SRDA-C00292-1

[10] Aitchison, J. and Silvey, S. (1957) The Generalization of Probit Analysis to the Case of Multiple Responses. Biometrika, 44, 131-140. https://doi.org/10.1093/biomet/44.1-2.131

[11] Maddala, G. (1983) Limited-Dependent and Qualitative Variables in Econometrics. Cambridge University Press, Cambridge. https://doi.org/10.1017/CBO9780511810176

[12] Duncan, A. (2000) Cross-Section and Panel Data Econometrics. Lectures and Seminar Programme Notes, University of Nottingham, Nottingham. 